Southern Illinois University Carbondale

OpenSIUC

Articles

Department of Plant, Soil, and Agricultural Systems

2012

\title{
Genetic Analysis of Root and Shoot Traits in the 'Essex' By 'Forrest' Recombinant Inbred Line (RIL) Population of Soybean [Glycine max (L.) Merr.]
}

William Brensha Brensha

Fayetteville State University

Stella K. Kantartzi

Southern Illinois University Carbondale

Khalid Meksem

Southern Illinois University Carbondale

Robert L. Grier IV

Fayetteville State University

Abdelali Barakat

Clemson University

See next page for additional authors

Follow this and additional works at: https://opensiuc.lib.siu.edu/psas_articles

Published in Journal of Plant Genome Sciences, Vol. 1 No.1 (2012) at doi: 10.5147/jpgs.2012.0051

\section{Recommended Citation}

Brensha, William Brensha, Kantartzi, Stella K., Meksem, Khalid, Grier, Robert L. IV, Barakat, Abdelali, Lightfoot, David A. and Kassem, My A. "Genetic Analysis of Root and Shoot Traits in the 'Essex' By 'Forrest' Recombinant Inbred Line (RIL) Population of Soybean [Glycine max (L.) Merr.]." (Jan 2012).

This Article is brought to you for free and open access by the Department of Plant, Soil, and Agricultural Systems at OpenSIUC. It has been accepted for inclusion in Articles by an authorized administrator of OpenSIUC. For more information, please contact opensiuc@lib.siu.edu. 
Authors

William Brensha Brensha, Stella K. Kantartzi, Khalid Meksem, Robert L. Grier IV, Abdelali Barakat, David A. Lightfoot, and My Abdelmajid Kassem 


\title{
Genetic Analysis of Root and Shoot Traits in the 'Essex" By 'Forrest' Recombinant Inbred Line (RIL) Population of Soybean [Glycine max (L.) Merr.]
}

\author{
Williams Brensha', Stella K. Kantartzi ${ }^{2}$, Khalid Meksem², Robert L. Grier IV ${ }^{\text {, Abdelali Bara- }}$ \\ kat $^{3}$, David A. Lightfoot ${ }^{2}$, and My Abdelmajid Kassem ${ }^{1 *}$
}

1 Plant Genomics and Biotechnology Lab, Department of Biological Sciences, Fayetteville State University, Fayetteville, NC 28301-4298, USA. ${ }^{2}$ Department of Plant, Soil and Agricultural Systems, Southern Illinois University, Carbondale, IL 62901-4415, USA. ${ }^{3}$ Department of Genetics and Biochemistry, Clemson University, Clemson, SC.

Received: May 27, 2011 / Accepted: October 12, 2011

\section{Abstract}

Crop productivity is severely reduced by water deficit and drought in many plant species including soybean. Improved root and shoot traits can contribute to drought tolerance ability of the plant. This research was conducted to identify QTL that underlie several root and shoot traits in the 'Essex' by 'Forrest' (ExF RILs, $n=94$ ) recombinant inbred line (RIL) soybean population. Field collected samples were used for gathering phenotypic data of basal root thickness (BRT), lateral root number (LRN), maximum root length (MRL), root fresh weight (RFW), root dry weight (RDW), shoot fresh weight (SFW), shoot dry weight (SDW), and calculating RFW/SFW, and $R D W / S D W$ ratios. All traits and ratios were compared against DNA markers using the composite interval mapping (CIM). A total of 12 QTL: 3 for MRL, 1 QTL for LRN, 1 QTL for BRT, 2 QTL for RFW, 2 QTL for RDW, 4 QTL for SFW, 3 QTL for SDW, and 3 QTL for SFW/SDW were identified and mapped on different linkage groups (LGs) A2, B2, C2, D1a, F, G, and N. The LOD scores of these QTL ranged from 2.5 to 6.0. No QTL were associated with RFW/RDW. The root and shoot trait QTL of this study may benefit breeding programs for producing cultivars tolerant to water deficit and high yield. Preliminary analyses of genes the QTL regions using $\mathbf{G O}$ annotation gave insight into genes that may underlie some of these QTLs.

Key Words: Soybean, QTL, basal root thickness, lateral root number, maximum root length, root fresh weight, root dry weight, shoot fresh weight, shoot dry weight.

\section{Introduction}

Water deficit and drought are serious problems worldwide that inhibit plant growth and crop productivity (Boyer 1982; Specht et al., 2001). Soybean [Glycine max (L.) Merr.], a valuable legume commodity crop rich in protein and oil suitable for human and animal consumption, can be affected considerably by water deficit and drought (Sinclair et al., 2007). Both improved root and shoot traits can contribute to drought tolerance ability of the plant. More specifically, long, thick, and extensive root systems contribute highly to drought tolerance (Specht et al., 2001; Ling et al., 2002; Li et al., 2005; Bing et al., 2005; Lambers et al., 2006). In addition, limiting water loss, via evaporation, from plant surfaces, maintaining turgor pressure, and protecting cytoplasmic proteins and membranes from desiccation contribute greatly to drought tolerance (Clawson et al., 1986; Specht et al., 2001). It has also been reported that ratios of root weight to shoot weight and root penetration ability were correlated with drought tolerance (Price et al., 1997; Li et al., 2005).

Conventional plant breeders have struggled for many years to improve root and shoot systems for providing farmers with cultivars of better quality, more productive, disease and drought tolerance. Nowadays biotechnology can help them with the application of new technologies to manipulate root and shoot traits in a more efficient way (Gahoonia and Nielsen, 2004).

Molecular markers have been widely used to identify quantitative trait loci (QTL) for important agronomic traits, particularly those that are polygenic in nature (Tanksley, 1993). In soybean, 
molecular markers were extensively used in the past decades to construct genetic linkage maps (Zhang et al., 2004; Song et al., 2004; Lightfoot et al., 2005; Kassem et al., 2006), physical maps (Shultz et al., 2006; Wu et al., 2004), transcript maps (Choi et al., 2007), and to both identify and confirm QTL for many agronomically important traits (SoyBase, 2011). QTL for root and shoot traits were reported in many plant species including rice (Li et al., 2005; Ashikari et al., 2005; MacMillan et al., 2006a,b), maize (Tuberosa et al., 2002; Hund et al., 2004; Zhu et al., 2006), Brassica (Cogan et al., 2002), Arabidopsis (Loudet et al., 2005), barley (Chloupek et al., 2006), Eucalyptus (Marques et al., 1999), wheat (An et al., 2006), and soybean (Kassem et al., 2004, 2006; SoyBase, 2011).

The objectives of this study were to investigate several phenotypic root and shoot traits and to identify the underlying QTL in the 'Essex $x$ Forrest' RIL soybean population.

\section{Materials and Methods}

\section{Experimental Population}

The development of the experimental RIL population used in the current study (ExF, $n=94)$ originated from two individual lines, 'Essex' and 'Forrest' (Schmidt et al., 1999). Essex and Forrest differ in many traits including the root and shoot traits. Forrest has a dense and extensive root system while Essex has a less dense root system (Figure 1) Briefly, the 'Essex' and 'Forrest' cross was made in 1983 at Southern Illinois University, Carbondale (SIUC) and advanced to the F5 generation by single seed descent (Lightfoot et al., 2005). One hundred recombinant inbred lines $(n=94)$ were selected from a pool of 500 F5 plants in 1989. Since then, these 100 RILs were used to construct the ExF genetic linkage maps and were evaluated to identify QTL for many agronomic traits (Lightfoot et al., 2005; Kassem et al., 2006).

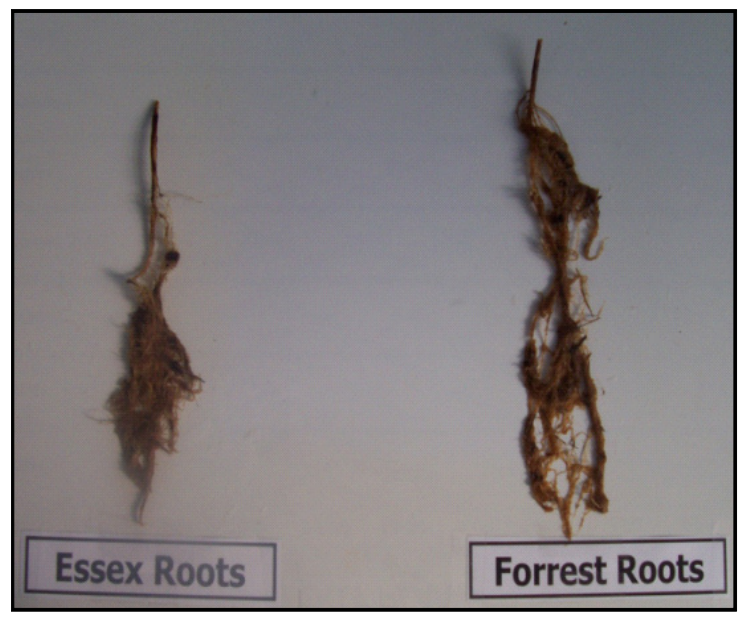

Figure 1. Comparison of the root systems of soybean cultivars 'Essex' and 'Forrest'. Forrest has an extensive root system compared to Essex. The root systems were photographed when the two cultivars reached full maturity in the field ( 112 days).
The majority of the lines in the population were registered, released (Lightfoot et al., 2005), and have been studied for a variety of traits (Kassem et al. 2004, 2006, 2007a, b; Jacobson et al., 2007). All lines that adopted in this study were kindly provided by Dr. Khalid Meksem of Southern Illinois University, Carbondale.

\section{Experiments and Traits Evaluation}

In April of 2010, four seeds of 'Essex', 'Forrest', and each RIL were grown in pots of $30 \mathrm{~cm}$ diameter containing PRO-MIX soil in the greenhouse. The PRO-MIX is a ready-made, peat based growing mix containing the Canadian Sphagnum Peat Moss (75-85\% by volume), perlite, vermiculite, limestone (for $\mathrm{pH}$ adjustment), and a wetting agent. The plants were kept for three weeks under controlled conditions of temperature $(25 \pm 10 \mathrm{C})$ and natural daylight.

Three weeks later, plants were transferred to field conditions in Spring Lake, NC (Harnett County, NC) and were arranged in a randomized complete block design with 3 replications. Each row was $2.7 \mathrm{~m}$ long with a spacing of $0.3 \mathrm{~m}$ between rows. The population density was 16 plants/m2 (160,000 plants/ha).

Roots and shoots from all RILs and parental lines were harvested close to the average harvest maturity of parents and all RILs (R8, 112 days after planting). The roots in the soil were handled with caution to prevent damage or loss. Five root traits (basal root thickness [BRT]; lateral root number [LRN] extending from the taproot; maximum root length [MRL]; root fresh weight $[R F W]$; root dry weight [RDW]) and two shoot traits (shoot fresh weight [SFW]; shoot dry weight [SDW] were measured as described previously in rice (Li et al., 2005). For the evaluation of root and shoot dry weight, plant samples (roots and shoots) were placed in an oven at $650 \mathrm{OC}$ for 48 hours. In addition, the ratio of root fresh weight to shoot fresh weight (RFW/SFW); and the ratio of root dry weight to shoot dry weight (RDW/RFW) were calculated.

\section{Phenotypic Data Analysis}

Data collected from parental lines and RILs were included in the statistical analysis. Descriptive statistics for all traits were calculated for RIL population and Pearson's correlation coefficients between all trait combinations were determined. Correlations were reported in a Pearson matrix. All analyses were performed by JMP 9.0.0 (SAS Institute Inc., Cary, NC, USA).

\section{Genotypic Data}

Young leaves from two-week-old RILs and parental lines were collected and DNA was extracted and simple sequence repeats (SSRs or microsatellites) analysis was carried on as reported previously in Kassem et al. (2006).

\section{QTL Analysis}

The root and shoot traits mapped in the ExF RIL population were BRT, LRN, MRL, RFW, RDW, SFW, SDW, along with RFW/ 
SFW, and RDW/RFW ratios. QTL mapping and estimation of their effects were generated using the method of composite interval mapping (CIM) of WinQTL Cartographer (Wang et al., 2005) adopting the Model 6 as well. The control marker number and window size were 5 and $10 \mathrm{cM}$, respectively. A walk speed of $2 \mathrm{cM}$ and the forward regression method were selected. LOD score peaks greater than 2.5 (WinQTL Cartographer default threshold) indicated the existence of QTL for all seven root and shoot traits plus the two ratios reported in this study. Experimentwise threshold levels to declare linkage were calculated from 1,000 permutations of each genotype marker against the phenotype in the population. Linkage was reported as significant if the two values for a marker were greater than the critical value at $P=0.05$.

\section{Identification of Genes in QTL Regions and GO Annotation}

The identification of genes within the QTL regions was performed as described earlier (Kassem et al., 2011). Briefly, each QTL was bounded by two single nucleotide polymorphism markers (SNPs). The SNP DNA sequences were obtained from the NCBI database (http://www.ncbi.nlm.nih.gov/projects/SNP/). A BLAST search of the Glycine max genome was performed (http://soybase.org/gbrowse/cgi-bin/gbrowse/gmax1.01/), and the gene names and descriptions were obtained (http:// soybase.org/gbrowse/cgi-bin/gbrowse/gmax1.01/) (Schmutz et al., 2000).

Soybean predicted coding DNA sequences (CDS) from QTL regions were retrieved from the phytozome website ( $w$ ww.phytozome.net/soybean) and were annotated by querying them against the Arabidopsis thaliana proteome (www.arabidopsis. org) using Blastx (Blastx, e-value < e-6). Functional classification of peach genes was performed using The Gene Ontology (GO) system (Consortium, 2008). To narrow the list of candidate genes, three biological processes (development, stress, biotic and abiotic stimuli) were retained as part of candidate genes to be considered further.

\section{Results}

\section{Performance of RILs}

Means, standard errors and coefficients of variation of RIL were calculated for all phenotypic root (BRT, LRN, MRL, RFW, RDW), shoot (SFW and, SDW) traits and ratios (RFW/SFW, and RDW/RFW) and presented in Table 1. The coefficients of variation ranged from $40.033 \%$ to $57.401 \%$ for root traits and from $43.660 \%$ to $73.562 \%$ for shoot traits.

\section{Correlation Coefficients Between Traits and Ratios}

Correlation coefficients were estimated for each pair-wise

Table 1. Root and shoot traits in a soybean recombinant inbred line population between Essex and Forrest evaluated at FSU Campus in 2010.

\begin{tabular}{lccccc}
\hline & \multicolumn{3}{c}{ RILs $(\mathbf{n = 9 4 )}$} & \multicolumn{2}{c}{ Parents } \\
Trait & Mean & StE & CV\% & Essex mean & Forrest mean \\
Root Fresh Weight (g) & 6.029 & 0.500 & 55.596 & 3.240 & 7.500 \\
Root Dry Weight (g) & 3.803 & 0.295 & 51.987 & 1.700 & 3.900 \\
Lateral Root Number & 31.778 & 2.503 & 52.840 & 41.000 & 34.000 \\
Max Root Length (cm) & 31.867 & 1.902 & 40.033 & 24.560 & 24.600 \\
Basal Root Thickness (cm) & 0.821 & 0.070 & 57.401 & 0.500 & 0.090 \\
RFW/RDW & 1.649 & 0.131 & 53.462 & 1.906 & 1.923 \\
Shoot Fresh Weight (g) & 37.926 & 3.804 & 67.298 & 19.024 & 25.500 \\
Shoot Dry Weight (g) & 25.204 & 2.764 & 73.562 & 11.740 & 16.560 \\
SFW/SDW & 1.712 & 0.111 & 43.660 & 1.620 & 1.539 \\
\hline
\end{tabular}

Table 2. Pearson correlation coefficients for all traits (BRT, LRN, MRL, RFW, RDW, SFW, and SDW) and ratios (RFW/ SFW and RDW/RFW) of 94 soybean recombinant inbred lines between Essex and Forrest evaluated at FSU Campus in 2010.

\begin{tabular}{|c|c|c|c|c|c|c|c|c|}
\hline Traits & $\begin{array}{c}\text { Root Dry } \\
\text { Weight }\end{array}$ & $\begin{array}{l}\text { Lateral } \\
\text { Root } \\
\text { Length }\end{array}$ & $\begin{array}{l}\text { Max Root } \\
\text { Length }\end{array}$ & $\begin{array}{l}\text { Basal Root } \\
\text { Thickness }\end{array}$ & RFW/RDW & $\begin{array}{l}\text { Shoot } \\
\text { Fresh } \\
\text { Weight }\end{array}$ & $\begin{array}{c}\text { Shoot Dry } \\
\text { Weight }\end{array}$ & SFW/SDW \\
\hline Root Fresh Weight & $0.850 * * *$ & $0.1325 \mathrm{~ns}$ & $0.296 * * *$ & $0.655^{* * *}$ & $0.222^{*}$ & $0.589^{* * *}$ & $0.616^{* * *}$ & $0.006 \mathrm{~ns}$ \\
\hline Root Dry Weight & & $0.273^{* *}$ & $0.144 \mathrm{~ns}$ & $0.625^{* * *}$ & $-0.183^{*}$ & $0.466^{* * *}$ & $0.705^{* * *}$ & $-0.181 *$ \\
\hline Lateral Root Number & & & $0.007 \mathrm{~ns}$ & $0.116 \mathrm{~ns}$ & $-0.074 \mathrm{~ns}$ & $0.079 \mathrm{~ns}$ & $0.248 * *$ & $-0.07 n s$ \\
\hline Max Root Length & & & & $0.250 * *$ & $0.102 \mathrm{~ns}$ & $0.182^{*}$ & $0.096 \mathrm{~ns}$ & $0.04 \mathrm{~ns}$ \\
\hline Basal Root Thickness & & & & & $0.027 \mathrm{~ns}$ & $0.527^{* * *}$ & $0.564^{* * *}$ & $0.037 \mathrm{~ns}$ \\
\hline RFW/RDW & & & & & & $0.089 \mathrm{~ns}$ & $-0.130 \mathrm{~ns}$ & $0.213^{*}$ \\
\hline Shoot Fresh Weight & & & & & & & $0.597^{* * *}$ & $0.390 * * *$ \\
\hline Shoot Dry Weight & & & & & & & & $-0.234^{* *}$ \\
\hline
\end{tabular}


Table 3. QTL of root and shoot traits in soybean: MRL, LRN, BRT, RFW, SDW, SFW, SDW, and SFW/SDW in the soybean ExF RIL population grown at FSU Campus, NC in 2010. No QTL were found for RFW/RDW.

\begin{tabular}{|c|c|c|c|c|c|c|c|}
\hline Trait & No. & LG & QTL & Marker/interval & Position (cM) & LOD & $\mathbf{R}^{2}(\%)$ \\
\hline \multirow[t]{3}{*}{ MRL } & 4 & $\mathrm{C} 2$ & qMRLOO 1 & Satt357-Satt202 & $0-27.2$ & 3.4 & 26.0 \\
\hline & 7 & & qMRLOO 2 & Satt239-Sat_105 & $174.4-187.7$ & 4.2 & 33.0 \\
\hline & 12 & $\mathrm{~N}$ & qMRLO03 & Satt530-Satt080 & $21.0-34.0$ & 2.7 & 17.0 \\
\hline LRN & $\left(\begin{array}{ll}1 & 1\end{array}\right)$ & G & qLRNOO 1 & Satt570-Satt1 22 & $66.0-73.2$ & 6.0 & 39.0 \\
\hline BRT & 11 & G & qBRTOO 1 & Satt570-Satt6 10 & $68.8-76.1$ & 2.9 & 12.0 \\
\hline \multirow[t]{2}{*}{ RFW } & 1 & $\mathrm{~A} 2$ & qRFW00 1 & BLT65-CCA1 6 & $17.0-26.0$ & 2.6 & 26.0 \\
\hline & $(2)$ & & qRFW002 & Satt177-Satt424 & $44.1-58.8$ & 2.8 & 20.0 \\
\hline \multirow[t]{2}{*}{ RDW } & (2) & $\mathrm{A} 2$ & qRDW00 1 & Satt177-Satt424 & $45.8-60.8$ & 3.7 & 34.0 \\
\hline & 12 & $\mathrm{~N}$ & qRDW002 & Satt485-Satt080 & $28.1-45.3$ & 2.6 & 19.0 \\
\hline \multirow[t]{4}{*}{ SFW } & $(2)$ & $\mathrm{A} 2$ & qSFW00 1 & Satt177-Satt424 & $44.1-56.2$ & 5.8 & 33.0 \\
\hline & 6 & $\mathrm{C} 2$ & qSFW002 & Satt520-Satt239 & $131.1-167.7$ & 2.9 & 29.0 \\
\hline & 8 & $D 1 a+Q$ & qSFW003 & Satt368-Satt267 & $22.4-34.0$ & 2.6 & 12.0 \\
\hline & 12 & $\mathrm{~N}$ & qSFW00 4 & Satt485-Satt387 & $36.4-49.4$ & 3.7 & 21.0 \\
\hline \multirow[t]{3}{*}{ SDW } & 2 & $\mathrm{~A} 2$ & qSDW00 1 & Satt177-Satt424 & $44.1-52.0$ & 6.0 & 34.0 \\
\hline & 10 & G & qSDW002 & Satt303-OEO 2 & $9.2-19.8$ & 2.5 & 18.0 \\
\hline & 12 & $\mathrm{~N}$ & qSDW003 & Satt485-Satt387 & $34.9-49.4$ & 3.5 & 18.0 \\
\hline \multirow[t]{3}{*}{ SFW/SDW } & 3 & B2 & qSFW/SDW00 1 & Sat_083-Satt3 18 & $23.4-30.7$ & 3.1 & 19.0 \\
\hline & 5 & $\mathrm{C} 2$ & qSFW/SDW002 & Satt363-Satt367 & $111.7-132.2$ & 2.9 & 20.0 \\
\hline & 9 & $\mathrm{~F}$ & qSFW/SDW003 & Satt1 60-Satt252 & $0-5.8$ & 2.7 & 15.0 \\
\hline
\end{tabular}

trait combination for Essex x Forrest RIL population (Table 2). The highest correlation was estimated for root fresh weight and root dry weight $\left(r=0.850^{* * *}\right)$ and the lowest but statistically significant between shoot fresh weight and maximum root length $(r=0.182 *)$. Both root fresh weight and root dry weight showed significant correlations $(P<0.05)$ with basal root thickness, RFW/ RDW, shoot fresh weight, and shoot dry weight. Interestingly, ratios RFW/RDW and SFW/SDW were not associated with lateral root number, maximum root length, and basal root thickness. It is worth mentioning that correlation of root fresh weight and maximum root length $\left(r=0.296^{* * *}\right)$ and shoot fresh weight and SFW/SDW ( $r=0.390 * * *)$ were moderate but highly significant. Finally, negative correlation was estimated for RFW/RDW and SFW/SDW ratios with root dry weight $\left(r=-0.183^{*}\right.$ and $r=$ $0.181 *)$, and also SFW $/$ SDW with shoot dry weight $\left(r=-0.234^{*}\right)$ at $\mathrm{P}<0.05$.

\section{QTL Mapping}

Approximately 600 soybean microsatellite markers were tested in 'Essex' and 'Forrest' DNA samples and of those 231 polymorphic markers were mapped in the RIL population. The current 'Essex' by 'Forrest' genetic linkage map consists of 368 SSR, RFLP, RAPD, and AFLP markers among which 231 are SSRs (Kassem et al., 2006, 2007a, b).

A total of 12 QTL for MRL, LRN, BRT, RFW, RDW, SFW, SDW, and SFW/SDW were identified on 7 different LGs (Table 3; Figure 2). These QTL have LOD scores ranging from 2.6 to 6.0 (Table 3). Three QTL were identified for MRL: two on LG C2 (chromosome 6) (qMRLO01 and qMRL002) and one on LG N (chromosome 3) (qMRL003) (Figure 2, Table 3). Together these three QTL explain about 76\% of the total variation in MRL (Table 3). The QTL on LG N (chromosome 3) controls also RDW (qRDW002), SFW (qSFW004), and SDW (qSDW003) (Table 3). On LG G (chromosome 18), one QTL underlies both LRN (qLRN001) and BRT (qBRT001) (Figure 2, Table 3). A third QTL that underlies SDW (qSDW002) was mapped approximately $46 \mathrm{cM}$ from the second QTL that underlies both LRN and BRT on LG G (Figure 2, Table 3). Two QTL were identified for RFW on LG A2 (chromosome 8); qRFW001 and qRFW002. These two QTL explain about $46 \%$ of the total variation in RFW (Table 3 ). Similarly, two QTL were identified for RDW; qRDW001 on LG A2 (chromosome 8) and qRDW002 on LG N (chromosome 3) (Figure 2, Table 3). These two QTL explain about $53 \%$ of the total variation in RDW (Table 3). Four QTL were identified for SFW; qSFW001 on LG A2 (chromosome 8), qSFW002 on LG C2 (chromosome 6), qSFW003 on LG DI a (chromosome 1), and qSFW004 on LG N (chromosome 3). These four QTL explain about $95 \%$ of the total variation in SFW (Table 3). Three QTL were identified for SDW; qSDW001 on LG A2 (chromosome 8), qSDW002 on LG G (chromosome 18), and qSDW003 on LG N (chromosome 3). Together, these four QTL explain about $70 \%$ of 


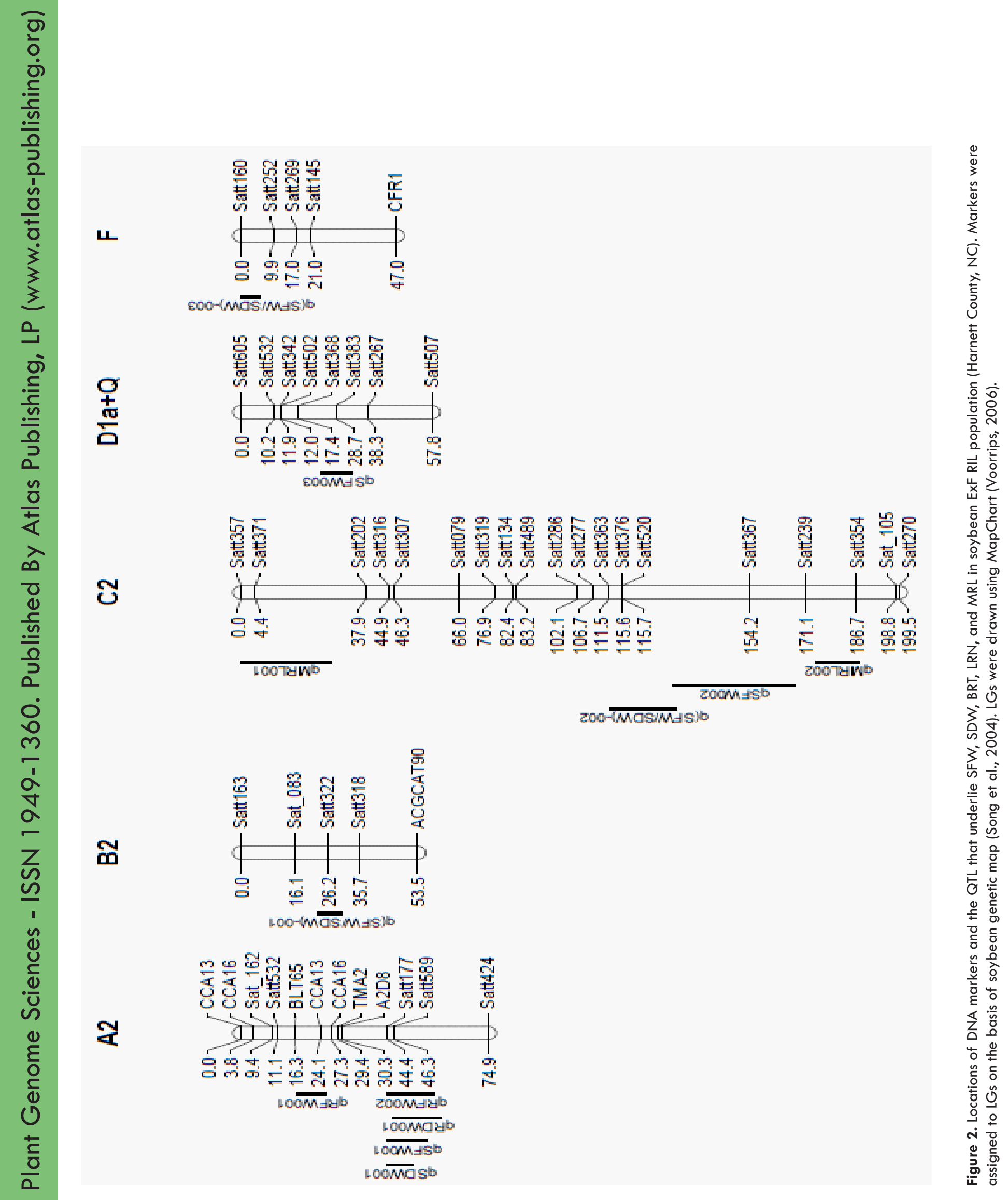




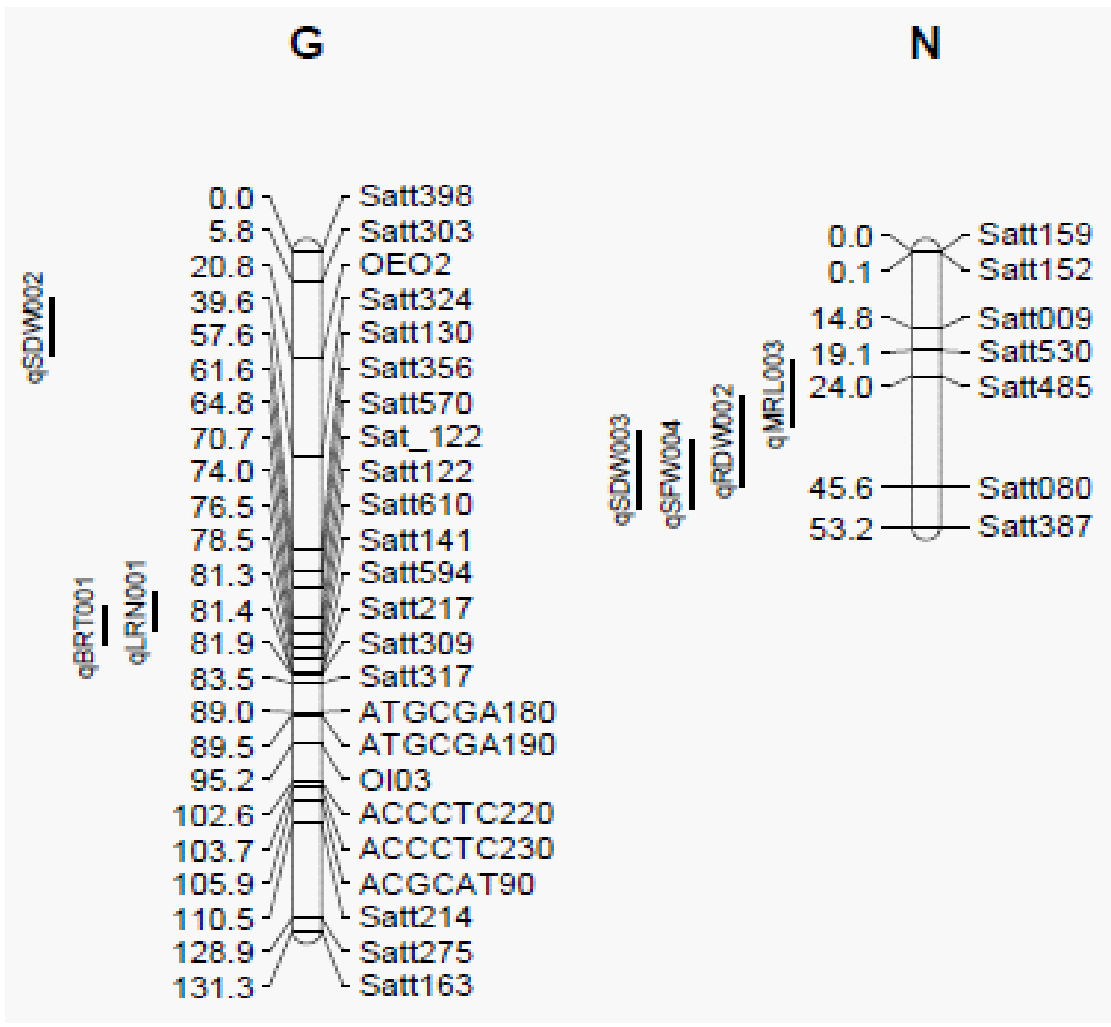

Figure 2. Continued.

the total variation in SDW (Table 3). Three QTL were identified for the ratio SFW/SDW; q(SFW/SDW)-001 on LG B2 (chromosome 14), q(SFW/SDW)-002 on LG C2 (chromosome 6), and q(SFW/SDW)-003 on LG F (chromosome 13). These three QTL explain about $44 \%$ of the total variation in SFW/SDW (Table 3).

Interestingly, clusters of QTL for the studied root and shoot traits were identified on LGs A2 (chromosome 8), C2 (chromosome 6), G (chromosome 18), and N (chromosome 3) (Figure 3). On LG A2, we identified a cluster of QTL for SDW, SFW, RDW, and RFW. Similarly, a cluster of QTL for SFW, MRL, and SFW/ SDW was identified on LG C2; a cluster of QTL for BRT and LRN was identified on LG G, and a cluster of QTL for SDW, SFW, RDW, and MRL was identified on LG N.

\section{Delimitation of QTL Regions and Analysis of Candidate Genes}

Comparative mapping showed that the QTL intervals delineated using mapping data ranged between 5.8 and $36.6 \mathrm{cM}$ (Table 3). Sequence analysis showed that these regions contain a number of genes varying between 9 and 46 genes (Table 4 Supplementary Data). The GO annotation allowed to classify genes based on their function and identify genes from three biological processes (developmental processes, responses to biotic and abiotic stresses, and signal transduction) that may be involved in root development or drought stress (Figure 3, Table 4 Supplementary data).

\section{Discussion}

The soybean ExF mapping population represents an advanced set of RILs and NILs based on southern US germplasm. The population was recently released for community use (Lightfoot et al., 2005) and the 2005-2006 version of the genetic map contained 368 polymorphic markers (Lightfoot et al., 2005; Kassem et al., 2007a, b). Using the 2006 map and WinQTL CART., a total of 12 QTL for 8 root and shoot traits were detected and mapped on 7 different LGs of the soybean genome. Clusters of QTL that underlie different traits were observed on several LGs and for several root and shoot traits studied which is in agreement with previous studies (Cregan et al., 1999). For example, a region spanning only $15 \mathrm{cM}$ on LG A2 (chromosome 8) contains a cluster of 4 QTL for RFW, RDW, SFW, and SDW. In this region, QTL for oil content, SCN resistance, seed coat hardness, seed weigh, and sucrose concentration have been identified and mapped (SoyBase, 2011).

Similarly, a region spanning $55 \mathrm{cM}$ on LG C2 (chromosome 6) contains QTL for seed yield, plant height, flowering time, pod maturity, seed isoflavones content, and SDS resistance (Primomo et al., 2005; SoyBase, 2011 ). The region spanning $11.6 \mathrm{cM}$ and containing qSFW003 on LG Dla (chromosome 1) contains also QTL for SCN resistance, oil content, seed weight, and two identified genes; one encoding for fatty acid desaturase 8 (FAD8-1, Li et al., 2008) and the second encoding for glutathione S-transferase (GST 13, Copeland et al., 2008) (SoyBase, 2011 ). The fourth cluster on LG N (Chromosome 3) containing qMRL002, 


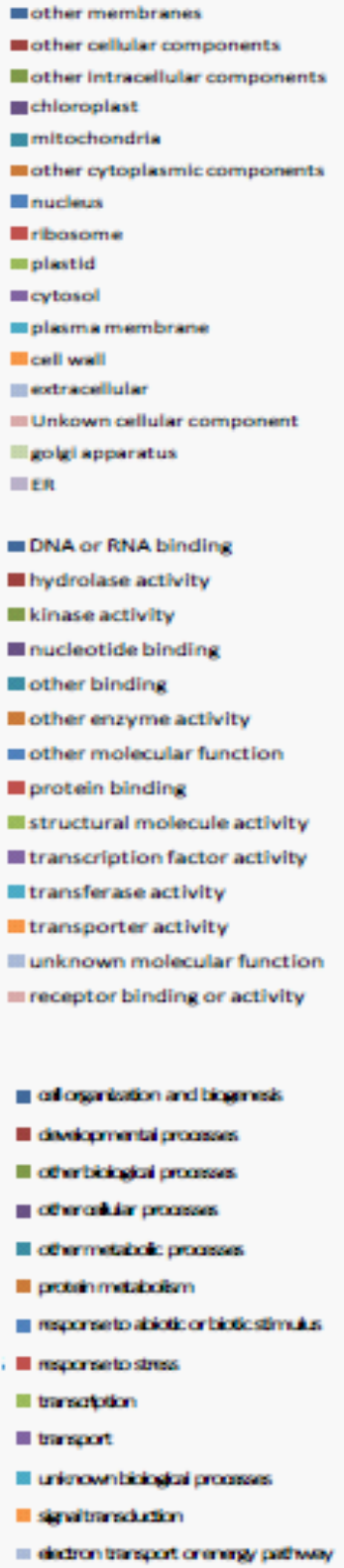

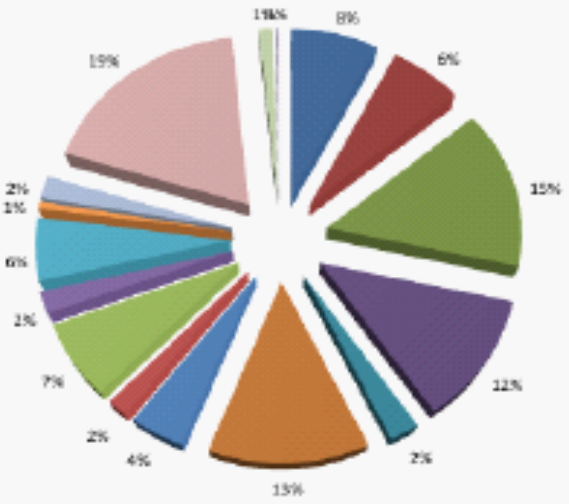
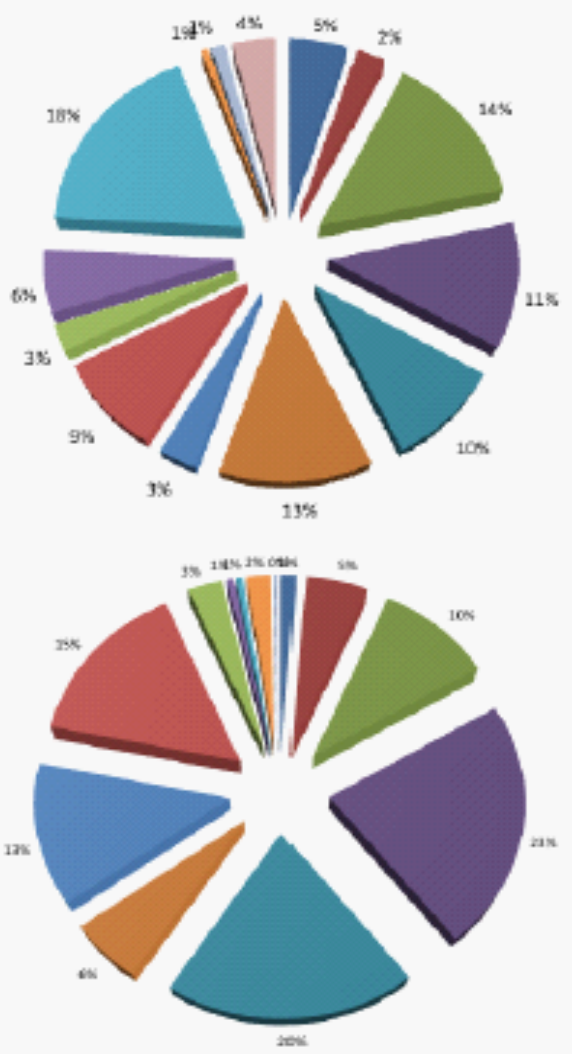

Molecular Functions

\section{Cellular Components}

Figure 3. Pie charts representation of Gene Ontology classification of putative molecular functions of predicted genes from the QTL the underlie root and shoot traits as well as the biological processes in which they are involved in.

qRDW002, qSFW004, and qSDW003 contains also QTL for leaf width, plant height, iron efficiency, SDS resistance, SCN resistance (SoyBase, 2011). The region contains 9 identified genes the encode for bZIP transcription factor (bZIP69) (Liao et al., 2008; SoyBase, 2011 ), rubisco activase (RCA03, Yin et al., 2010; SoyBase, 2011), fatty acid desaturase 8 (FAD8-1, Li et al., 2008; SoyBase, 2011), cultivar Williams AIR 12 (Preger et al., 2009; SoyBase, 2011), cw5 NB-LRR and cw6 TIR-NBS-LRR disease resistance type disease resistance proteins (Jeong et al., 2001; Li et al., 2008; SoyBase, 2011), nucleoside diphosphate kinase (Mehus et al., 1999; SoyBase, 2011), phantastica transcription factor b (PHANb, Puzio et al., 2009; SoyBase, 2011), beta-tubulin (S-beta-2, Guiltinan et al., 1987) and glutathione S-transferase (GST 13, Copeland et al., 2008; Soybase, 2011). Interestingly, two of these genes are also common to the region containing qSFWOO3 on LG Dla (chromosome 1). These two genes are fatty acid desaturase 8 (FAD8-1, Li et al., 2008; Soybase, 2011) and glutathione S-transferase (GST 13, Copeland et al., 2008; SoyBase, 2011).

Numerous other genes were identified in the regions containing root and shoot QTL; however, based on the GO annotation, these genes were classified into genes involved in developmental processes, responses to biotic and abiotic stresses, and signal transduction. A few examples of genes involved in developmen- 
tal processes are genes that encode a formylglycinamidine ribonucleotide synthase (Mutwil et al., 2010), a MYB-domain protein involved in specification of the leaf proximodistal axis (Ikezaki et al., 2010), a deltal-pyrroline-5-carboxylate synthase that catalyzes the rate-limiting enzyme in the biosynthesis of proline (Van Leene et al., 2010), and a heat shock protein 90 (HSP90) that is abundant in root apical meristems (Prasad et al., 2010). For genes involved in responses to biotic and abiotic processes, examples are genes encoding for a disease resistance protein (TIR-NBS-LRR class) (Meyers et al., 2003), a Rubisco activase (Barta et al., 2010), a glutamine-dependent asparagine synthetase that is expressed mainly in shoot tissues (Hanson et al., 2008), a calcium/calmodulin-regulated receptor-like kinase important for cold tolerance (Yang et al., 2010). For genes involved in signal transduction, examples are genes that encode for a disease resistance protein (TIR-NBS-LRR class) (Meyers et al., 2003), a receptor-like protein kinase (Kobe \& Kajava, 2001), a calmodulin-domain protein kinase (Nühse et al., 2003), and a leucine-rich repeat receptor kinase (Zybailov et al., 2008) to name a few (Table 4 Supplementary data).

QTL for BRT, RFW, RDW, MRL, RFW/SFW, LRN, RDW/SDW, and IDR (index of drought resistance; Li et al. 2005), and other root traits were identified and mapped in other plant species as in rice (MacMillan et al., 2006a, b), tomato (Brommonschenkel et al., 2000; Doganlar et al., 2002), and maize (Guingo et al., 1998; Landi et al., 2002; Hund et al., 2004).

Knowing that drought is a serious problem that considerably limits plant growth and crop productivity in many parts of the world (Boyer 1982; Specht et al., 2001), mapping QTL and finding genes that control root and shoot traits is of extreme importance (Specht et al., 2001; Ling et al., 2002; Li et al., 2005). With this in mind, the root and shoot traits QTL found here are important when introduced in soybean breeding programs to produce improved cultivars or germplasm lines with competitive yield, tolerant to drought.

\section{Acknowledgments}

The authors would like to thank Pam Ratcliff, Fridia Desernay, Ronald Williams, James Walker, and Kimberly Hargraves for their help with growing the population and taking care of the plants in the field and the greenhouse.

\section{References}

An D, J Su, Q Liu, Y Zhu, Y Tong, J Li, R Jing, B Li, and Z Li (2006) Mapping QTLs for nitrogen uptake in relation to the early growth of wheat (Triticum aestivum L.). Plant and Soil 284: 73-84.

Arabidopsis Proteome (2011). http://www.arabidopsis.org. Last accessed January 2011.

Ashikari M, H Sakakibara, S Lin, T Yamamoto, T Takashi, A Nishimura, ER Angeles, Q Qian, H Kitano, and M Matsuoka (2005) Cytokinin oxidase regulates rice grain production. Science 309: 741-745.

Bing Y, L Xiong, W Xue, Y Xing, L Luo, and C Xu (2005) Genetic analysis for drought resistance of rice at reproductive stage in field with different types of soil. Theor Appl Genet 111: 1127-1136.

Boyer JS (1982) Plant productivity and environment. Science 218: $443-448$.
Brommonschenkel SH, A Frary, and SD Tanksley (2000) The broad-spectrum tospovirus resistance gene $\mathrm{Sw}-5$ of tomato is a homolog of the root-knot nematode resistance gene. Mol Plant-Microbe Interactions 13 (10): $1130-1138$.

Chloupek O, BP Forster, and WTB Thomas (2006) The effect of semidwarf genes on root system size in field-grown barley. Theor Appl Genet 112: 779-786.

Choi IY, DL Hyten, LK Matukumalli, Q Song, JM Chaky, CV Quigley, K Chase, KG Lark, RS Reiter, MS Yoon, EY Hwang, SI Yi, ND Young, RC Shoemaker, CP Van Tassel, JE Specht, and PE Cregan (2007) A Soybean Transcript Map: Gene Distribution, Haplotype and SingleNucleotide Polymorphism Analysis. Genetics 176:685-696.

Clawson KL, JE Specht, BL Blad, and AF Garay (1986) Water use efficiency in soybean pubescence density isolines - a calculation procedure estimating daily values. Agron J 78: 483-487.

Cogan N, J Lynn, G King, M Kearsey, H Newbury, and I Puddephat (2002) Identification of genetic factors controlling the efficiency of Agrobacterium rhizogenes mediated transformation in Brassica oleracea by QTL analysis. Theor Appl Genet 105: 568-576.

Copeland A, S Lucas, A Lapidus, T Glavina del Rio, E Dalin, H Tice, D Bruce, L Goodwin, S Pitluck, O Chertkov, T Brettin, JC Detter, C Han, CR Kuske, J Schmutz, F Larimer, M Land, L Hauser, N Kyrpides, A Lykidis, D Emerson, and P Richardson (2008) Complete sequence of Leptothrix cholodnii SP-6. US DOE Joint Genome Institute, GeneBank Submission.

Cregan PB, T Jarvik, A Bush, RC Shoemaker, KG Lark, AL Kahler, N Kaya, TT VanToai, DG Lohnes, J Chung, and JE Specht (1999) An integrated genetic linkage map of the soybean genome. Crop Sci 39: 1464-1490.

Doganlar S, A Frary, HM Ku, and SD Tanksley (2002) Mapping quantitative trait loci in inbred backross lines of Lycopersicon pimpinellifolium (LA1589). Genome 45: 1189-1 202.

Gahoonia TS, and NE Nielse (2004) Root traits as tools for creating phosphorus efficient crop varieties. Plant \& Soil 260: 47-57.

Gene Ontology System (2008) http://www.geneontology.org/ GO.consortiumlist.shtml.

Guiltinan MJ, D-PP Ma, RF Barker, MM Bustos, RJ Cyr, R Yadegari, and $D E$ Fosket (1987) The isolation, characterization and sequence of two divergent beta-tubulin genes from soybean (Glycine max L.). Plant Mol Biol 10: 171-184.

Guingo A, Y Hebert, and A Charcosset (1998) Genetic analysis of root traits in maize. Agronomy J 18: 225-235.

Hund A, Y Fracheboud, A Soldati, E Frascaroli, S Salvi, and P Stamp (2004) QTL controlling root and shoot traits of maize seedlings under cold stress. Theor Appl Genet 109: 618-629.

Jeong SC, AJ Hayes, RM Biyashev, and MA Saghai Maroof (2001) Diversity and evolution of a non-TIR-NBS sequence family that clusters to a chromosomal "hotspot" for disease resistance genes in soybean. Theor Appl Genet 103: 406-414.

Kassem MA, J Shultz, K Meksem, Y Cho, AJ Wood, MJ lqbal, and DA Lightfoot (2006) An updated 'Essex' by 'Forrest' linkage map and first composite map of QTL underlying six soybean traits. Theor Appl Genet 113: 1015-1026.

Kassem MA, K Meksem, AJ Wood, and DA Lightfoot (2007a) A Microsatellite map developed from late maturity germplasm 'Essex' by 'Forrest' detects four QTL for soybean seed yield expected from early maturing germplasm. Rev Biol \& Biotech 6 (1): 2-10.

Kassem MA, K Meksem, AJ Wood, and DA Lightfoot (2007b) Additional QTL for SDS and SCN resistances in a soybean recombinant inbred line population of Essex $x$ Forrest. Rev in Biol \& Biotech 6(1): 11-19.

Kassem MA, K Meksem, CH Kang, VN Niiti, V Kilo, AJ Wood, and DA Lightfoot (2004) Loci underlying resistance to manganese toxicity mapped in a recombinant inbred line population of 'Essex' $x$ 'For- 
rest'. Plant and Soil 260: 197-204.

Lambers H, MW Shane, MD Cramer, SJ Pearse, and EJ Veneklaas (2006) Root structure and functioning for efficient acquisition of phosphorus: matching morphological and physiological traits. Annals of Botany 98: 693-713.

Landi P, MC Sanguinetti LL Darrah, MM Giuliani, S Salvi, S Conti, and R Tuberosa (2002) Detection of QTLs for vertical root pulling resistance in maize and overlap with QTLs for root traits in hydroponics and for grain yield under different water regimes. Maydica 47: 233-243.

Li Z, P Mu, C Li, H Zhang, Z Li, Y Gao, and X Wang (2005) QTL mapping of root traits in a doubled haploid population from a cross between upland and lowland japonica rice in three environments. Theor Appl Genet 110: 1244-1252.

Li W, W Chang, and Y Han (2008) Some cold-related genes of soybean. GeneBank.

Li W, W Chang, Y Han, and S Bao (2008) Isolation of a candidate disease-resistance gene from soybean. GeneBank.

Liao Y, HF Zou, W Wei, YJ Hao, AG Tian, J Huang, YF Liu, JS Zhang, and SY Chen (2008) Soybean GmbZIP44, GmbZIP62 and GmbZIP78 genes function as negative regulator of $A B A$ signaling and confer salt and freezing tolerance in transgenic Arabidopsis. Planta 228 (2): $225-240$.

Lightfoot DA, VN Njiti, PT Gibson, MA Kassem, JM lqbal, and K Meksem (2005) Registration of the Essex by Forrest Recombinant Inbred Line Mapping Population. Crop Sci 45: 1678-1681.

Ling ZM, ZC Li, R Yu, and P Mu (2002) Agronomic root characters of upland rice and paddy rice (Oryza sativa L.). J Chin Agric Univ 7: 7-11.

Loudet O, V Gaudon, A Trubuil, and FD Vedele (2005) Quantitative trait loci controlling root growth and architecture in Arabidopsis thaliana confirmed by heterogeneous inbred family. Theor Appl Genet 110: 742-753.

MacMillan K, K Emrich, HP Piepho, CE Mullins, and AH Price (2006a) Assessing the importance of genotype by environment interaction for root traits in rice using a mapping population II: conventional QTL analysis. Theor Appl Genet 113: 953 -964.

MacMillan K, K Emrich, HP Piepho, CE Mullins, and AH Price (2006b) Assessing the importance of genotype by environment interaction for root traits in rice using a mapping population I: a soil-filled box screen. Theor Appl Genet 113: 977-986.

Marques CM, JV Kool, VJ Carocha, JG Ferreira, DM O'Malley, BH Liu, and R Sederoff (1999) Genetic dissection of vegetative propagation traits in Eucalyptus tereticornis and E. globules. Theor Appl Genet 99: 936-946.

Matsuda O, H Sakamoto, Y Nakao, K Oda, and K Iba (2009) CTD phosphatases in the attenuation of wound-induced transcription of jasmonic acid biosynthetic genes in Arabidopsis. Plant J 57 (1): 96-108.

Mehus JG, P Deloukas, and DO Lambeth (1999) NME6: a new member of the nm23/nucleoside diphosphate kinase gene family located on human chromosome 3p21.3. Human Genetics 104 (6): 454-459.

Phytozome (201 1). http://www.phytozome.net/soybean. Last accessed January 2011.
Preger V, N Tango, C Marchand, SD Lemaire, D Carbonera, M Di Valentin, A Costa., P Pupillo, and P Trost (2009) Auxin-Responsive Genes AIR 12 Code for a New Family of Plasma Membrane b-Type Cytochromes Specific to Flowering Plants. Plant Physiology 150 (2): 606-620.

Price AH, DS Virk, and AD Tomos (1997) Genetic dissection of root growth in rice (Oryza sativa L.). I: a hydroponic screen. Theor Appl Genet 95: 132-142.

Puzio P, A Blau, TB Walk, M Gipsmans, V Haake, A Weig, G Plesch, and $M$ Ebneth (2009) Process for the production of a fine chemical. Patent: EP 2090662-A2 120033 19-AUG.

Shultz J, D Kurunam, K Shopinski, MJ Iqbal, S Kazi, K Zobrist, R Bashir, $S$ Yaegashi, N Lavu, A Afzal, C Yesudas, MA Kassem, C Wu, HB Zhang, CD Town, K Meksem, and DA Lightfoot (2006) The Soybean Genome Database (SoyGD): Physical Maps, Genetic Maps, Homeologous Regions, DNA Markers, Contig Structures, EST Content, BAC End Sequences and Contiguous DNA Sequences Of Glycine max. Nucleic Acids Res 34: D758-D765.

Sinclair TR, LC Purcell, CA King, CH Sneller, P Chen, and V Vadez (2007) Drought tolerance and yield increase of soybean resulting from improved symbiotic N2 fixation. Field Crops Research 101: 68-71.

Song QJ, LF Marek, RC Shoemaker, KG Lark, VC Concibido, X Delannay, JE Specht, and PB Cregan (2004) A new integrated genetic linkage map of the soybean. Theor Appl Genet 109: 122-128.

SoyBase (2011) http://soybase.agron.iastate.edu. Last accessed in January 2011.

Specht JE, K Chase, M Macrander, GL Graef, J Chung, JP Markwell, M Germann, JH Orf, and KG Lark (2001) Soybean Response to Water: A QTL Analysis of Drought Tolerance. Crop Sci 41: 493-509.

Tanksley SD (1993) Mapping polygenes. Annu Rev Genet 27: 205-233. Tuberosa R, MC Sanguineti, P Landi, MM Giuliani, S Salvi, and S Conti (2002) Identification of QTLs for root characteristics in maize grown in hydroponics and analysis of their overlap with QTLs for grain yield in the field at two water regimes. Plant Mol Biol 48: 697-712.

Voorrips RE (2002) MapChart: Software for the graphical presentation of linkage maps and QTLs. The Journal of Heredity 93 (1): 77-78.

Wang S, CJ Basten, and ZB Zeng (2005) Windows QTL Cartographer 2.5. Department of Statistics, NCSU, Raleigh, NC. (http://statgen. ncsu.edu/qtlcart/WQTLCart.htm).

Wu C, S Sun, P Nimmakayala, FA Santos, K Meksem, R Springman, K Ding, DA Lightfoot, and HB Zhang (2004) A BAC- and BIBAC-based physical map of the soybean genome. Genome Res 14: 319-326.

Yin Z, F Meng, H Song, X Wang, X Xu, and D Yu (2010) Expression quantitative trait loci analysis of two genes encoding rubisco activase in soybean. Plant Physiology 152 (3): 1625-1637.

Zhang WK, YJ Wang, GZ Luo, JS Zhang, CY He, XL Wu, JY Gai, and SY Chen (2004) QTL mapping of ten agronomic traits on the soybean (Glycine max L. Merr.) genetic map and their association with EST markers. Theor Appl Genet 108: 1131-1139.

Zhu J, SM Mickelson, SM Kaeppler, and JP Lynch (2006) Detection of quantitative trait loci for seminal root traits in maize (Zea mays L.) seedlings grown under differential phosphorus levels. Theor Appl Genet 113: 1-10. 